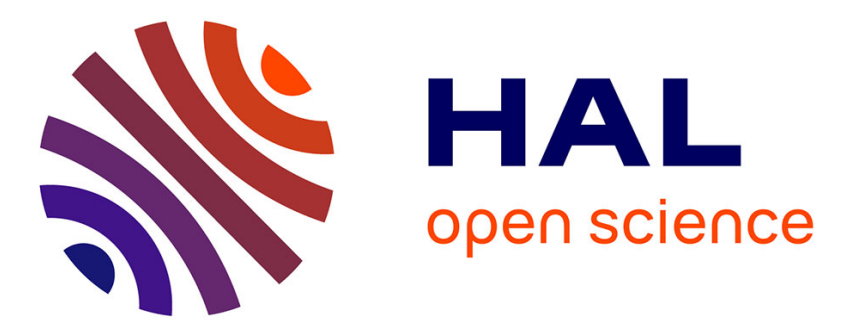

\title{
Brain molecular imaging in pharmacoresistant focal epilepsy: Current practice and perspectives
}

\author{
A. Verger, S. Lagarde, L. Maillard, Fabrice Bartolomei, Eric Guedj
}

\section{To cite this version:}

A. Verger, S. Lagarde, L. Maillard, Fabrice Bartolomei, Eric Guedj. Brain molecular imaging in pharmacoresistant focal epilepsy: Current practice and perspectives. Revue Neurologique, 2018, 174 (1-2), pp.16-27. 10.1016/j.neurol.2017.05.001 . hal-02479834

\section{HAL Id: hal-02479834 \\ https://hal.science/hal-02479834}

Submitted on 21 Apr 2020

HAL is a multi-disciplinary open access archive for the deposit and dissemination of scientific research documents, whether they are published or not. The documents may come from teaching and research institutions in France or abroad, or from public or private research centers.
L'archive ouverte pluridisciplinaire HAL, est destinée au dépôt et à la diffusion de documents scientifiques de niveau recherche, publiés ou non, émanant des établissements d'enseignement et de recherche français ou étrangers, des laboratoires publics ou privés. 


\section{Brain molecular imaging in pharmaco-resistant focal epilepsy: current practice and perspectives}

Verger A. MD, $\mathrm{PhD}^{1,2}$; Lagarde S. MD, $\mathrm{PhD}^{3}$; Maillard L. MD, $\mathrm{PhD}^{4}$; Bartolomei F. MD, $\mathrm{PhD}^{3,5}$, Guedj E. MD, $\mathrm{PhD}^{6,7,8}$.

${ }^{1}$ Department of Nuclear Medicine \& Nancyclotep Imaging platform, CHRU Nancy, Lorraine University, France

${ }^{2}$ IADI, INSERM, UMR 947, Lorraine University, Nancy, France

${ }^{3}$ APHM, Timone Hospital, Clinical Neurophysiology, Marseille, France

${ }^{4}$ Neurology Department, Nancy, France

5 Aix Marseille Univ, Inserm, INS, Institut de Neurosciences des Systèmes, UMR-S 1106, Marseille, France

${ }^{6}$ APHM, Timone Hospital, Department of Nuclear Medicine, France

7 Aix Marseille Univ, CNRS, INT, Institut des Neurosciences de la Timone, UMR 7289, Marseille, France

${ }^{8}$ Aix-Marseille Univ, CERIMED, Marseille, France

\section{General Review}

Words count: 4214

Address for correspondence:

Eric Guedj, M.D., Ph.D.

eric.guedj@ap-hm.fr

Service Central de Biophysique et Médecine Nucléaire, Hôpital de la Timone, 264 rue Saint Pierre, 13005 Marseille, France.

Tel: +33-491385558; Fax: +33-491384769 


\begin{abstract}
This review aims at synthetizing data available in brain molecular imaging, i.e. Single Photon Emission Computer Tomography (SPECT) but also inter-ictal Fluoro-Deoxy-Glucose Positron Emission Tomography (FDG PET) in focal epilepsies. SPECT imaging is able to measure regional cerebral blood flow and its major originality remains its ictal imaging value. On the other hand, FDG PET, which has higher spatial resolution and lower background activity than SPECT, enables to define glycolytic metabolism in inter-ictal state. Therefore, inter-ictal FDG PET has higher sensitivity than inter-ictal SPECT, especially in temporal lobe epilepsies (TLE). ${ }^{18}$ F-FDG PET is thus a necessary step in pre-surgical evaluation in TLE but also in extra-temporal epilepsies (ETE) leading to contribute to more than $30 \%$ in decision of surgery. In addition, FDG PET provides a particular diagnostic value in focal epilepsy with normal MRI. Moreover, PET has a good prognostic value on post-surgical outcome as well as cognitive impairment, especially in case with limited hypometabolism extent. The notion of epileptic network is also well underlined by functional imaging, allowing to better understand substrates of this pathology. Future development of quantitative analysis software, novel radiotracers and cameras will certainly enhance its clinical utility.
\end{abstract}

Key-words: Brain molecular imaging; SPECT; FDG-PET; pharmaco-resistant focal epilepsy. 


\section{Introduction}

Seventy million people in the world suffer from epilepsy, with 34 to 76 new cases diagnosed per 100,000 every year (1). Focal epilepsies are the most common forms and they are characterized by seizure onset localized in a region (the epileptogenic zone, EZ) of the cerebral cortex. Focal seizures are generally characterized by the emergence of rapid discharges occurring within networks either discretely localized or more widely distributed $(2,3)$. Overall, more than $30 \%$ of patients with epilepsy are thought to have drug-resistant seizures (1). In this context, surgical resection of the EZ is a valid option if the potential benefit is assessed to outweigh the risk (4). This EZ corresponds to the brain area necessary and sufficient for the generation of habitual seizures, generally less extensive than the whole irritative zone (area generating the inter-ictal spikes) (5). A medico-economic analysis shows, that in addition to being safe and effective, surgery of epilepsy is cost-effective in the medium term, and should therefore be considered earlier in the treatment of refractory epilepsies (6).

Pre-operative evaluation aims to precisely define EZ. In this line, surgical techniques have been refined over years with the help of non-invasive techniques such as High-Resolution electroencephalography (EEG) and Magnetoencephalography (7,8), magnetic resonance imaging (MRI), as well as invasive techniques such as Stereotactic electroencephalography (SEEG; a stereotactic guiding for the placement of depth electrodes for intracerebral EEG monitoring). This evaluation also includes brain molecular imaging with perfusion SPECT (single photon emission computed tomography), and/or metabolic PET (positron emission

tomography) using ${ }^{18}$ F-FDG $\left({ }^{18}\right.$ F-Fluorodeoxyglucose $)$. This global approach has led to more precise localization of EZ, allowing the removal of the minimal necessary amount of tissue with reduction of post-operative neurological deficit (9). It is noteworthy that surgical final decision is taken after interpretation of all these data within multidisciplinary staff discussion. 
In this context, this review aims at synthetizing data available in brain molecular imaging, i.e. SPECT but also inter-ictal FDG PET in focal pharmaco-resistant epilepsies (temporal (TLE) and extra-temporal (ETE)). Future perspectives would also be discussed for ${ }^{18}$ F-FDG PET analysis and novel PET radiopharmaceuticals. 


\section{SPECT in focal epilepsy}

SPECT imaging is able to measure regional cerebral blood flow (rCBF) associated with epileptic seizures (10). In this indication, its major originality remains its ictal imaging value. Actually, the radiopharmaceutical administration can be performed during an epileptic discharge, with a brain uptake irreversibly completed in one to two minutes (11). During an "ictal" scan, the brain regions involved in seizure generation and early propagation demonstrates increased perfusion, while most epileptic networks are hypoperfused during inter-ictal state (12). ${ }^{99 \mathrm{~m}}$ Technetium radiolabeled tracers such as HMPAo (HexaMethylPropyleneAmine oxime) or ECD (Ethyl Cystine Dimer) are currently used. SPECT image acquisition can start 30 to 90 minutes after injection with acquisition duration of about 20 minutes, and a radiation dosimetry of approximately $6 \mathrm{mSv}$ (13).

Ictal SPECT has shown a sensitivity of $73 \%$ and specificity of $75 \%$, while inter-ictal SPECT has a much lower localization value with $50 \%$ of sensitivity and $75 \%$ of specificity (14). Moreover, SPECT has higher performances in detection of epileptic networks in temporal epilepsies in comparison to non-temporal epilepsies, in ictal as well as in inter-ictal state (15). Subtraction of ictal and inter-ictal SPECT, co-registered to MRI (SISCOM), is particularly useful (Figure 1); this has been shown to improve the sensitivity and specificity of seizure localization networks only demonstrating hypoperfusion during inter-ictal scan (16). In this line, studies found that SISCOM localization sensitivity was higher than $90 \%$ in temporal lobe seizures, but much lower in extra-temporal lobe epilepsies $(17,18)$. Similarly, SISCOM provides useful information for seizure localization in patients with focal cortical dysplasia, even with normal MRI (19). Notably, ictal SPECT seems also suitable in children with focal refractory epilepsies associated with focal cortical dysplasia (20). 
Several studies have assessed the practical clinical value of SISCOM in preoperative evaluation, comparing SISCOM with either MRI, PET, ictal EEG or EEG-fMRI, surgical site or combined modalities (21-24). For instance, hyperperfusions from SISCOM images were localized more often than with side-by-side SPECT evaluation (71.0 vs. 47.4\%) (21), whereas SISCOM images led to a concordant or only slightly worth results than PET, MRI and EEG modalities alone or combined (22-24). Interestingly, if SISCOM localization is concordant with the surgical resection site or other traditional techniques, then postoperative outcomes are expected to be favorable (25-28).

Nevertheless, spatial resolution of SPECT is poor. Consequently, inter-ictal studies in focal epilepsies are currently performed with PET imaging which leads to a better sensitivity in detection of epileptic networks (29). This statement could be revised in future with instrumentation development, particularly Cadmium-Zinc-Telluride (CZT) cameras. They provide semi-conductors detectors with better sensitivity of detection, spatial and energy resolution (30).

\section{2. ${ }^{18}$ F-FDG PET in focal epilepsy}

PET has higher spatial resolution and lower background activity than SPECT (31). Therefore, inter-ictal PET has higher sensitivity than inter-ictal SPECT, as described in a previous metaanalysis by Spencer, especially in temporal lobe epilepsies (84 vs. $66 \%$ ) (29). One complementary explanation for this better sensitivity could also be the uncoupling of blood perfusion and metabolism, leading to more reduction in regional cerebral glucose metabolic rates than in regional cerebral perfusion. It could also be related to a shorter reversibility in perfusion state during inter-ictal phase (32). Evidence for this uncoupling was demonstrated 
in prior studies using ${ }^{15} \mathrm{O}-\mathrm{H}_{2} \mathrm{O}$ and ${ }^{18} \mathrm{~F}$-FDG PET $(33,34)$, and using ratio imaging of interictal ${ }^{99 \mathrm{~m}}$ Tc HMPAO SPECT divided by ${ }^{18}$ F-FDG PET $(32,35)$.

However, even if some studies have explored ictal ${ }^{18}$ F-FDG-PET (36), the temporal resolution of ${ }^{18}$ F-FDG-PET remains weak, with a longer uptake period (30 minutes), leading to a mixture of inter-ictal-, ictal-, and postictal-phase images (31), which rends difficult the analyze of ictal ${ }^{18}$ F-FDG-PET. Some studies have nevertheless correlated interical PET hypometabolism with clinical epileptic semiology such as déjà-vu in TLE or hyperkinetic seizures in ETE $(37,38)$.

${ }^{18}$ F-FDG PET, which evaluates the cerebral metabolic rate for glucose (CMRGlc), visually demonstrates the whole irritative zone (i.e. the EZ and subsequent neural networks involved in the generation of inter-ictal paroxysms) (39). The fact that ${ }^{18}$ F-FDG PET sensitivity differs according to the site of the epileptogenic area is nevertheless a strong argument against a causal relationship between hypometabolism and epileptogenicity (40). Inter-ictal hypometabolism topography may be indeed related to the neuronal networks involved by ictal discharge onset and also spread pathways (41). But the origin of this hypometabolism is certainly multifactorial and several mechanisms have been hypothesized: neuronal loss in the functional deficit zone, hypometabolic macro- or microscopic lesions, decreased synaptic activity (diaschisis), deafferentation with reduced numbers of synapses, post-ictal metabolic depression (40), presence of a lesion, even if controversial by atrophy and focal volume effect $(42,43)$, and breakdown of the inhibitory mechanisms at an advanced stage of the disease process (44). In this line, a dysfunction of neurotransmitter gamma-aminobutyric acid type A $\left(\mathrm{GABA}_{\mathrm{A}}\right)$ receptor has been established in human focal epilepsy (45). This dysfunction was modulated by glycolysis, explaining the hypometabolism induced by a decrease of inhibitory mechanisms, leading to facilitate epileptic discharges. Lastly, this hypometabolism is also influenced by the delay from the last seizure, frequency of the ictal discharge, duration of the 
seizure, and antiepileptic therapeutics (46). Actually, clinicians have to take into account these factors during the analysis of inter-ictal ${ }^{18}$ F-FDG PET.

Besides these PET findings, extension of hypometabolism to regions beyond the temporal lobe is often seen in patients with TLE $(47,48)$, suggesting that hypometabolism on PET scan shows a dysfunctional neural network wider than only the EZ (49). In this context, Chassoux et al. observed in 114 patients with TLE and hippocampal sclerosis, that regardless of the structural alterations, the topography of hypometabolism correlated strongly with the extent of epileptic networks when compared to electro-clinical data (50). Otherwise, authors found remotely hypermetabolism, predominant in non-epileptic lobe and extra-temporal areas, suggesting compensatory mechanisms to cognition impairment (51-55).

Briefly, ${ }^{18} \mathrm{~F}$-FDG PET imaging is performed after a 10 to 15 minutes resting state. Then, ${ }^{18} \mathrm{~F}$ FDG is injected and acquisitions, during about 15 minutes, start 30 to 60 minutes after injection, with a radiation dosimetry of approximately $2.9 \mathrm{mSv}(56)$.

Similarly to SPECT imaging and consequently to technological innovations, PET imaging will further improve their characteristics with the introduction of digital PET which provides better image quality, diagnostic confidence, and accuracy than analog PET. They support a spatial resolution of $4 \mathrm{~mm}$ and a lesion maximum SUV (Standard Uptake Value) 36\% higher and lesion-to-blood-pool SUV ratio 59\% higher than with conventional PET (57).

We will now discuss ${ }^{18}$ F-FDG PET indications in temporal and extra-temporal epilepsies, its relation with electroencephalography and MRI findings as well as its prognosis value.

\section{$2.1{ }^{18}$ F-FDG PET in Temporal Lobe Epilepsies (TLE)}


Temporal lobe epilepsies (TLE) are the most common form of focal epilepsies. ${ }^{18}$ F-FDG PET has a high sensitivity for TLE with a detection range from 86 to 90\% (58-61). For instance, in a 25 TLE patients study, Knowlton et al. showed that ${ }^{18}$ F-FDG PET was the most EEG correlated parameter with a sensitivity of detection of $87 \%$ (59), when compared to MRI (hippocampal volumetry, T2 relaxometry, and proton magnetic resonance spectroscopic imaging). However, so called TLE does not appear to be homogeneous from an electroclinical point of view $(5,62)$. They can be divided into 4 distinct subgroups: mesial (mTLE), lateral, temporal "plus" and bitemporal TLE (41). For instance, mTLE, the most frequent form of TLE (63), has proven to be one of the most medically refractory localization related to epilepsy syndromes (64). Then, in a study of 50 TLE patients, Chassoux et al. defined 4 groups of electro-clinical patterns, accordingly to distinct patterns of TLE previously mentioned, and showed a good accordance with inter-ictal ${ }^{18}$ F-FDG PET hypometabolisms at group-level (39). Moreover, in this study, the strictly mesial temporal hypometabolism had the most favorable outcome. Several studies have performed simultaneous ${ }^{18}$ F-FDG PET acquisitions and EEG recordings but the benefit remains nevertheless controversial $(65,66)$. Although, it has been suggested that, besides its invasiveness and its limited sampling, SEEG correlates better with ${ }^{18}$ F-FDG PET findings than EEG (65), leading to direct comparison between ${ }^{18}$ F-FDG PET findings and SEEG (67). In this context, authors found correspondence between SEEG findings and metabolic PET characterization at the group level; they validated also the results at individual level with a high accuracy of $71.4 \%$ to 88.2 $\%$ (41). As expected, the hypometabolism was not limited to the EZ defined by SEEG, underlying larger epileptic networks (41). More recently, authors have directly compared ictal high frequencies oscillations (HFO) recorded by SEEG with hypometabolism in inter-ictal ${ }^{18}$ F-FDG PET, and showed that temporal hypometabolic regions are more likely to present high frequencies oscillations (68). Consequently, the authors suggested that inter-ictal FDG- 
PET hypometabolism and ictal high frequencies oscillations (HFO) may share common pathophysiologic mechanisms (68).

Because of the different electro-clinical presentations of the TLE, ${ }^{18}$ F-FDG PET appears as a very useful tool in these epilepsies. In a study of 117 patients with drug refractory epilepsy, ${ }^{18}$ F-FDG PET helped in surgical decision-making in $68.8 \%$ of TLE, and was particularly efficient in case of mesial temporal sclerosis lesion (69).

\section{$2.2{ }^{18}$ F-FDG PET in Extra-Temporal Lobe Epilepsies (ETE)}

Extra-temporal lobe epilepsies (ETE) are less frequent than TLE, and frontal lobe epilepsies (FLE) constitute the most common form of ETE (63). Visual assessment of ${ }^{18}$ F-FDG PET rates from 38 to $67 \%$ according to ETE studies $(60,70,71)$ and, similarly to TLE, hypometabolism in ${ }^{18} \mathrm{~F}$-FDG PET is worse in patients with structural lesions than in patients without one (70). In this line, it is noteworthy that ${ }^{18}$ F-FDG PET is of particular interest in the patients with epilepsies associated with focal cortical dysplasia, even in children (72-77). This hold true for a wide spectrum of malformations of cortical development including polymicrogyria whose the heterogenous epileptogenicity correlates well with the heterogenous pattern of hypo and isometabolism $(78,79)$. In addition, as reported in a study of 117 patients, ETE exhibited less great concordance with electro-clinical data $(28.6 \%)$ in comparison to TLE (78.0\%) (69). Nevertheless, in a study involving 13 children, Silva et al. showed a sensitivity and specificity of ${ }^{18}$ F-FDG PET of $92 \%$ and $62.5 \%$ respectively (80). This high sensitivity detection was mostly due to the fact that children with FLE also frequently exhibited glucose metabolic abnormalities outside the frontal lobes. In a study of 194 patients with refractory epilepsy, involving 66 FLE and 38 others ETE, Rathore et al. showed that the proportion of abnormal ${ }^{18} \mathrm{~F}-\mathrm{FDG}$ PET was of $52 \%$ in FLE and $61 \%$ in other 
ETE, lower than in TLE (67\%). Moreover, concerning the usefulness of PET in further decision making, ${ }^{18}$ F-FDG PET data were useful in respective $38 \%$ of FLE, $50 \%$ of other ETE and $63 \%$ of TLE (81). The authors argued that certain ETE locations such as the mesiofrontal, occipital and operculo-insular regions are difficult to detect with ${ }^{18}$ F-FDG PET. This relative weak sensitivity of ETE detection has led to the use of quantitative analysis in order to improve diagnosis confidence $(82,60)$, although it remains debated (70).

If ETE detection appears less sensitive than TLE with ${ }^{18}$ F-FDG PET, pathophysiology of these epilepsies are also complex with extensive network involved, including mesial temporal areas $(82,71)$. In this line, $22 \%$ of patients with ETE exhibited temporal hypometabolism in a study by Hartl and al (83), mostly associated with temporal inter-ictal epileptic discharges (64\% of temporal hypometabolism). Interpretation of inter-ictal FDG-PET results requires thus consideration of EEG results and seizure semiology since common temporal glucose hypometabolism in ETE patients may reflect a remote epileptic dysfunction arising from extra-temporal epileptogenic zones.

\section{3. ${ }^{18}$ F-FDG PET and MRI}

In a significant number of cases, MRI do not reveal any epileptogenic lesion (84), even using 7 tesla MRI (85), although about $26 \%$ of patients with refractory focal epilepsies remains "MRI-negative" (86). In this context of normal MRI, authors showed nevertheless a focal or lateralized regional hypometabolism in PET, concordant to the ictal electroclinical data in 27 patients with various types of intractable epilepsies (41.5\%) (69). Similarly, in cases of drug resistant TLE with normal MRI, the surgical outcome has been found to be better in case of temporal hypometabolism. An example of multimodality pre-operative assessment of a TLE in a patient with normal MRI is given in Figure 3. 
Several studies have specifically analyzed post-surgery outcome of these patients with PET positive and normal MRI. They observed that patients with positive PET had similar rates of good outcome (Engel $\mathrm{I}=$ seizure-free) regardless of the presence or absence of a MRI detectable lesion $(67,87)$ and close to the surgical prognosis of patients with hippocampal sclerosis (88). In this line, patients with positive PET, even if associated to MRI negative data, should be considered as potential candidates to surgery. Moreover, the MRI is often reviewed in the light of PET findings, with the opportunity to co-register the two complementary imaging modalities, as currently recommended in the pre-surgical evaluation of intractable epilepsy $(89,90)$. An example is provided in Figure 2 These two modalities are indeed complementary rather than redundant since hypometabolism in ${ }^{18} \mathrm{~F}$-FDG PET was not related with severity of hippocampal sclerosis nor temporal atrophy defined on MRI $(39,43,91,92)$. The interest of FDG-PET/MRI coregistration was also highlighted in patients with focal cortical dysplasia, especially in younger patients with temporal localization who exhibit larger hypometabolism on 18F-FDG-PET $(73,93)$. In a study of 23 patients operated for intractable focal epilepsy associated with focal cortical dysplasia and normal MRI, the use ${ }^{18}$ F-FDG PET led to the detection of the lesion in $95 \%$ of the patients (75). Then, ${ }^{18}$ F-FDG PET exhibited not only hypometabolism in $78 \%$ cases, but also led to the detection of 4 additional cases when using co-registration with MRI, which is efficient and routinely available. More recently, an initial hybrid PET-MRI experience has increased diagnostic yields for detection of EZ (94). Authors suggested that it could be due to the unique advantage of improved coregistration, and simultaneous review of both structural and molecular data.

\section{4. ${ }^{18}$ F-FDG PET and clinical outcome}


${ }^{18}$ F-FDG PET is a part of the systematic pre-surgical assessment of drug-resistant epilepsies. A study based in surgical-decision-making has shown that $31.6 \%$ patients were directly selected for surgery based on PET contribution (69). ${ }^{18}$ F-FDG PET was more helpful in surgical decision-making in TLE (68.8\% of cases), than in ETE (23.3\% of cases) (69). As previously discussed, clinical outcome of patients with positive PET findings and MRI negative is similar to those with positive MRI data $(67,87)$.

Moreover, the post-operative status is also influenced by PET findings. In a meta-analysis of 46 studies, authors showed that PET hypometabolism ipsilateral to the EZ in TLE had a predictive value of $86 \%$ for good outcome (Engel classes I or II after surgery) (49). However, if the usefulness of ${ }^{18}$ F-FDG PET to accurate localize epileptic networks is well-established leading to good outome (95), the prognostic value of hypometabolism extent remains debated. In a 30 TLE patients study, Dupont et al. observed a better clinical outcome after surgery if the hypometabolism extent was limited (96). Similarly, patients with TLE and normal MRI, those with a good outcome had a greater proportion of total hypometabolic volume resected than those with a poor outcome (24.1\% versus $11.8 \%)(97)$. On the opposite, in a study analyzing associations between PET findings and neocortical epilepsies surgery outcome, authors showed no significant correlations between the amount of non-resected ${ }^{18}$ F-FDG PET abnormalities and the surgical outcome (98). It is noteworthy that this last study included ETE, which are known to have more subsequent remote hypometabolism (83). On the whole, ${ }^{18}$ F-FDG PET has a good prognostic value on post-surgical outcome, especially in case with limited hypometabolism extent $(96,97)$.

Besides its prognostic value on post-surgical outcome, ${ }^{18} \mathrm{~F}$-FDG PET also allows to explore cerebral networks involved in epilepsy and their link with the cognitive alterations in TLE. First studies with ${ }^{18}$ F-FDG PET have shown an association between decrease of metabolic 
value and cognition impairment in $\operatorname{TLE}(99,100)$. Then, correlations have been shown between cognitive impairment and metabolic values of hippocampal or para-hippocampal areas $(101,102)$. Otherwise, studies focusing on extra-temporal hypometabolism in TLE have also been conducted, showing association between: left temporal pole hypometabolism and memory of famous faces (103), left temporo-occipital areas hypometabolism and deficit on word findings (104), or prefrontal areas hypometabolism and impairment of executive functions (105). In a study of 15 TLE patients with hippocampal sclerosis, authors have observed correlations between number of correctly recognized targets in a new recognition memory paradigm and inter-ictal entorhinal/perirhinal cortices metabolic rate for glucose (55).

In ETE, a ${ }^{18}$ F-FDG PET study in 9 patients with occipital lobe epilepsy has revealed verbal memory impairment selectively associated with left temporal lobe hypometabolism, supporting a link between neuropsychological dysfunction and remote hypometabolism in focal epilepsies (106). Therefore, in addition to prognostic value on seizure control outcome, ${ }^{18}$ F-FDG PET provides a prognostic value on cognition: a limited hypometabolism, particularly in limbic areas, being a better prognostic factor for post-operative cognitive functioning $(101,102,55)$.

\section{Analysis of ${ }^{18}$ F-FDG PET imaging}

Visual assessment remains the gold standard for detection of hypometabolism in epilepsy, regards to expert interpretation and discussion with clinicians based on other available data. SPECT SISCOM (16) and co-registration between PET and MRI $(89,90)$ have already been discussed previously, and could be particularly contributive. In some cases, quantitative analysis could also be helpful (107-110), especially for extra-temporal epilepsies $(60,70)$. 
Some studies analyzed inter-hemispheric asymmetries, such as left to right subtraction, or the asymmetry index, and showed improvement of preoperative evaluations for TLE. In most such studies, inter-hemispheric asymmetry was calculated from the mean region-of-interest value or the volume-of-interest $(111,112)$ whereas other studies have applied asymmetries to voxel-based analysis (113). Voxel-based quantitative analysis is a valuable tool to detect subsequent epileptic networks by voxel-to-voxel comparison of two PET image dataset (60). An example of quantitative analysis is available in Figure 4. In a study of 41 patients with epilepsy, Van't Klooster et al. showed that, although sensitivity of detection was similar between visual assessment and quantitative analysis, this last procedure detected 4 on 5 initially visual defined negative scans (108). The authors concluded that quantitative analysis could be an efficient complementary tool to visual assessment. The choice of quantitative analysis software does not appear to really influence results while an original algorithm of spatial normalization (107) or a fully-automated software of quantitative analysis (110) exhibited similar results to the well-validated software Statistical Parametric Mapping (114). Some authors have proposed thresholds with liberal p-values and restrictive cluster sizes in order to maximize accuracy of these quantitative analyses (109).

In addition to particularly useful co-registration to MRI previously described above $(89,90)$, taking into account focal volume effect, induced by lower spatial resolution in PET, is also efficient. In this line, Goffin et al. showed that using reconstruction algorithm with inclusion of focal volume effect improved visual detection of epileptic networks on brain ${ }^{18}$ F-FDG PET images, in particular setting of focal cortical dysplasia, due to higher contrast and better delineation of the lesion (115).

6. Novel PET imaging radiotracers for epilepsy 
In addition to ${ }^{18}$ F-FDG PET imaging, novel PET radiotracers have been developed in epilepsy, especially in research. They need for this purpose a radiochemistry platform next-to the PET imaging center.

${ }^{11}$ C-flumazenil (FMZ) PET studies targeting GABA $_{\mathrm{A}}$-central benzodiazepine receptor complex (GABAAcBZR) have demonstrated reduced binding of tracer in the epileptic networks of patients $(116,117) .{ }^{11}$ C-FMZ PET failed nevertheless to detect epileptic networks in $20 \%$ of patients with refractory TLE and normal high-quality MRI in a study performed by Koepp et al. (118), and its reproducibility is debated especially when using pons as a reference tissue (119).

Several studies have been conducted with 2'-methoxyphenyl-(N-2'-pyridinyl)-p-fluorobenzamidoethyipiperazine $\left({ }^{18} \mathrm{~F}-\mathrm{MPPF}\right)$ which is an antagonist of 5-HT1A receptors $(120,121)$. 5-HT1A receptors are decreased in patients with epilepsy compared with normal subjects leading to a decrease of ${ }^{18} \mathrm{~F}-\mathrm{MPPF}$ uptake in epileptic networks. Therefore, this decrease is highly correlated to the degree of epileptogenicity of cortical areas explored by intracerebral EEG recordings and does not reflect only pathological changes or neuronal loss in the epileptic focus, by underlining epileptic network $(120,121)$.

Otherwise, by using a non-selective opioid receptor antagonist, ${ }^{11} \mathrm{C}$-diprenorphine (DPN), authors have experimented a post-ictal increase in ${ }^{11} \mathrm{C}$-DPN in the parahippocampal gyrus ipsilateral to the epileptic focus. Thus, this study provides further direct human in vivo evidence for changes in opioid receptor availability in TLE following seizures (122).

Moreover, metabotropic glutamate receptor type 5 (mGluR5) abnormalities have been described in tissue resected from epilepsy patients with focal cortical dysplasia. In a recent study, ${ }^{11} \mathrm{C}-\mathrm{ABP} 688$, a radiotracer of mGluR5, showed in vivo evidence of reduced mGluR5 
availability in focal cortical dysplasia, indicating focal glutamatergic alterations in malformations of cortical development (123).

Neuro-inflammation has also been studied in epilepsy. In this context, ${ }^{11} \mathrm{C}-\mathrm{PBR} 28$ and ${ }^{11} \mathrm{C}$ DPA-713, radiotracers of Translocator protein $18 \mathrm{kDa}$ (TSPO), had increased uptake in both areas ipsilateral and contralateral to seizure networks in patients with TLE, suggesting an inflammatory effect in this epilepsies (124).

Others studies involving N-methyl-d-aspartate (NMDA) receptors, which are ligand-gated and voltage-gated ion channels that mediate fast excitatory neurotransmission in the central nervous system, have been performed. In this line, increased NMDA channel activation was detected in patients with focal epilepsy by using ${ }^{18} \mathrm{~F}-\mathrm{GE}-179$, a ligand that selectively binds to the open NMDA receptor ion channel (125).

Among all these novel radiotracers, ${ }^{11} \mathrm{C}$-alpha-methyl-L-tryptophan (AMT) is the most studied and validated (126-128). ${ }^{11} \mathrm{C}$-AMT is a radiolabeled tryptophan analogue to study synthesis of serotonin in the brain. Inter-ictal PET studies have demonstrated a focal increased uptake of this radiotracer in epileptogenic areas (126-128). Focal increase of cortical ${ }^{11} \mathrm{C}$ AMT uptake is nevertheless less sensitive but more specific for the lobe of seizure onset than corresponding ${ }^{18} \mathrm{~F}$-FDG PET hypometabolism (128). It is also often associated with epileptogenic cortical developmental malformations (128). Thus ${ }^{11} \mathrm{C}$-AMT can assist placement of intracranial electrodes even when MRI and FDG-PET fail to provide adequate localizing information.

However, despite their many advantages, majority of non-FDG brain PET studies are not widely available and performed in limited centers only as they require well experienced staff with on-site radiochemistry equipment and cyclotron. Moreover, novel tracers using 
neurotransmitter are highly influenced by medications interactions, especially in patients with anti-epileptic therapies (129).

\section{Conclusion}

To conclude, brain molecular imaging and especially ${ }^{18}$ F-FDG PET imaging, is a valuable tool for epilepsy imaging, widely studied and validated. ${ }^{18}$ F-FDG PET is thus a necessary step in pre-surgical evaluation in TLE but also in ETE leading to contribute to more than $30 \%$ in decision of surgery. Its association with others pre-surgical data such as MRI or electroclinical data improves its accuracy during the multi-disciplinary staff discussion. Moreover, ${ }^{18}$ F-FDG PET imaging provides an interesting prognostic value in clinical outcome and with potential cognitive impairment association. The notion of epileptic network is also well underlined by this functional imaging, allowing to better understand substrates of this pathology. Future development of quantitative analysis software, novel radiotracers and cameras will certainly enhance its clinical utility.

\section{Conflict of interest: None}

\section{Acknowledgements:}

This work has been carried out thanks to the support of the A*MIDEX project ( ${ }^{\circ}$ ANR-11IDEX-0001-02) funded by the «Investissements d'Avenir » French Government program, managed by the French National Research Agency (ANR), and thanks to Cyclopharma grant. 
This work has been carried out within the FHU EPINEXT with the support of the A*MIDEX project (ANR-11-IDEX-0001-02) funded by the "Investissements d'Avenir" French Governement program managed by the French National Research Agency (ANR).

\section{References}

1. Weaver DF, Pohlmann-Eden B. Pharmacoresistant epilepsy: unmet needs in solving the puzzle(s). Epilepsia. 2013 May;54 Suppl 2:80-5.

2. Berg AT, Berkovic SF, Brodie MJ, Buchhalter J, Cross JH, van Emde Boas W, et al. Revised terminology and concepts for organization of seizures and epilepsies: report of the ILAE Commission on Classification and Terminology, 2005-2009. Epilepsia. 2010 Apr;51(4):676-85.

3. Wendling F, Chauvel P, Biraben A, Bartolomei F. From intracerebral EEG signals to brain connectivity: identification of epileptogenic networks in partial epilepsy. Front Syst Neurosci. 2010;4:154.

4. Kwan P, Brodie MJ. Early identification of refractory epilepsy. N Engl J Med. 2000 Feb 3;342(5):314-9.

5. Bartolomei F, Wendling F, Vignal JP, Kochen S, Bellanger JJ, Badier JM, et al. Seizures of temporal lobe epilepsy: identification of subtypes by coherence analysis using stereo-electroencephalography. Clin Neurophysiol Off J Int Fed Clin Neurophysiol. 1999 Oct;110(10):1741-54.

6. Picot M-C, Jaussent A, Neveu D, Kahane P, Crespel A, Gelisse P, et al. Cost-effectiveness analysis of epilepsy surgery in a controlled cohort of adult patients with intractable partial epilepsy: A 5-year follow-up study. Epilepsia. 2016 Oct;57(10):1669-79.

7. Rikir E, Koessler L, Gavaret M, Bartolomei F, Colnat-Coulbois S, Vignal J-P, et al. Electrical source imaging in cortical malformation-related epilepsy: a prospective EEG-SEEG concordance study. Epilepsia. 2014 Jun;55(6):918-32.

8. Gavaret M, Maillard L, Jung J. High-resolution EEG (HR-EEG) and magnetoencephalography (MEG). Neurophysiol Clin Clin Neurophysiol. 2015 Mar;45(1):105-11.

9. West S, Nolan SJ, Newton R. Surgery for epilepsy: a systematic review of current evidence. Epileptic Disord. 2016 Jun;(2):113-121. 
10. Sasaki K, Ohsawa Y, Sasaki M, Kaga M, Takashima S, Matsuda H. Cerebral cortical dysplasia: assessment by MRI and SPECT. Pediatr Neurol. 2000 Nov;23(5):410-5.

11. Leonard JP, Nowotnik DP, Neirinckx RD. Technetium-99m-d, 1-HM-PAO: a new radiopharmaceutical for imaging regional brain perfusion using SPECT--a comparison with iodine-123 HIPDM. J Nucl Med Off Publ Soc Nucl Med. 1986 Dec;27(12):1819-23.

12. Devous MD, Thisted RA, Morgan GF, Leroy RF, Rowe CC. SPECT brain imaging in epilepsy: a meta-analysis. J Nucl Med Off Publ Soc Nucl Med. 1998 Feb;39(2):285-93.

13. Kapucu ÖL, Nobili F, Varrone A, Booij J, Vander Borght T, Någren K, et al. EANM procedure guideline for brain perfusion SPECT using $99 \mathrm{mTc}$-labelled radiopharmaceuticals, version 2 . Eur J Nucl Med Mol Imaging. 2009 Dec;36(12):2093-102.

14. Spanaki MV, Spencer SS, Corsi M, MacMullan J, Seibyl J, Zubal IG. Sensitivity and specificity of quantitative difference SPECT analysis in seizure localization. J Nucl Med Off Publ Soc Nucl Med. 1999 May;40(5):730-6.

15. Newton MR, Berkovic SF, Austin MC, Rowe CC, McKay WJ, Bladin PF. SPECT in the localisation of extratemporal and temporal seizure foci. J Neurol Neurosurg Psychiatry. 1995 Jul;59(1):26-30.

16. O'Brien T, O'Connor MK, Mullan BP, Brinkmann BH, Hanson D, Jack CR, et al. Subtraction ictal SPET co-registered to MRI in partial epilepsy: Description and technical validation of the method with phantom and patient studies. Nucl Med Commun. 1998 Jan;19(1):31-46.

17. Harvey AS, Hopkins IJ, Bowe JM, Cook DJ, Shield LK, Berkovic SF. Frontal lobe epilepsy: clinical seizure characteristics and localization with ictal 99mTc-HMPAO SPECT. Neurology. 1993

Oct;43(10):1966-80.

18. Harvey AS, Bowe JM, Hopkins IJ, Shield LK, Cook DJ, Berkovic SF. Ictal 99mTc-HMPAO Single Photon Emission Computed Tomography in Children with Temporal Lobe Epilepsy. Epilepsia. 1993 Sep;34(5):869-77.

19. O'Brien TJ, So EL, Cascino GD, Hauser MF, Marsh WR, Meyer FB, et al. Subtraction SPECT coregistered to $\mathrm{MRI}$ in focal malformations of cortical development: localization of the epileptogenic zone in epilepsy surgery candidates. Epilepsia. 2004 Apr;45(4):367-76.

20. Krsek P, Kudr M, Jahodova A, Komarek V, Maton B, Malone S, et al. Localizing value of ictal SPECT is comparable to MRI and EEG in children with focal cortical dysplasia. Epilepsia. 2013 Feb;54(2):351-8.

21. Kaiboriboon K, Lowe VJ, Chantarujikapong SI, Hogan RE. The Usefulness of Subtraction Ictal SPECT Coregistered to MRI in Single- and Dual-headed SPECT Cameras in Partial Epilepsy. Epilepsia. 2002 Apr 22;43(4):408-14.

22. Véra P, Kaminska A, Cieuta C, Hollo A, Stiévenart JL, Gardin I, et al. Use of subtraction ictal SPECT co-registered to MRI for optimizing the localization of seizure foci in children. J Nucl Med Off Publ Soc Nucl Med. 1999 May;40(5):786-92.

23. Bouilleret V, Valenti MP, Hirsch E, Semah F, Namer IJ. Correlation between PET and SISCOM in temporal lobe epilepsy. J Nucl Med Off Publ Soc Nucl Med. 2002 Aug;43(8):991-8. 
24. Sierra-Marcos A, Maestro I, Falcón C, Donaire A, Setoain J, Aparicio J, et al. Ictal EEG-fMRI in localization of epileptogenic area in patients with refractory neocortical focal epilepsy. Epilepsia. 2013 Sep;54(9):1688-98.

25. Bell ML, Rao S, So EL, Trenerry M, Kazemi N, Stead SM, et al. Epilepsy surgery outcomes in temporal lobe epilepsy with a normal MRI. Epilepsia. 2009 Sep;50(9):2053-60.

26. Ahnlide J-A, Rosén I, Lindén-Mickelsson Tech P, Källén K. Does SISCOM Contribute to Favorable Seizure Outcome after Epilepsy Surgery? Epilepsia. 2007 Mar;48(3):579-88.

27. O'Brien TJ, So EL, Mullan BP, Cascino GD, Hauser MF, Brinkmann BH, et al. Subtraction periictal SPECT is predictive of extratemporal epilepsy surgery outcome. Neurology. $2000 \mathrm{Dec}$ 12;55(11):1668-77.

28. Kudr M, Krsek P, Marusic P, Tomasek M, Trnka J, Michalova K, et al. SISCOM and FDG-PET in patients with non-lesional extratemporal epilepsy: correlation with intracranial EEG, histology, and seizure outcome. Epileptic Disord. 2013 Mar;(1):3-13.

29. Spencer SS. The relative contributions of MRI, SPECT, and PET imaging in epilepsy. Epilepsia. 1994;35 Suppl 6:S72-89.

30. Verger A, Djaballah W, Fourquet N, Rouzet F, Koehl G, Imbert L, et al. Comparison between stress myocardial perfusion SPECT recorded with cadmium-zinc-telluride and Anger cameras in various study protocols. Eur J Nucl Med Mol Imaging. 2013 Feb;40(3):331-40.

31. Kim S, Mountz JM. SPECT Imaging of Epilepsy: An Overview and Comparison with F-18 FDG PET. Int J Mol Imaging. 2011;2011:813028.

32. Zubal IG, Avery RA, Stokking R, Studholme C, Corsi M, Dey H, et al. Ratio-images calculated from interictal positron emission tomography and single-photon emission computed tomography for quantification of the uncoupling of brain metabolism and perfusion in epilepsy. Epilepsia. 2000 Dec;41(12):1560-6.

33. Leiderman DB, Balish M, Sato S, Kufta C, Reeves P, Gaillard WD, et al. Comparison of PET measurements of cerebral blood flow and glucose metabolism for the localization of human epileptic foci. Epilepsy Res. 1992 Nov;13(2):153-7.

34. Fink GR, Pawlik G, Stefan H, Pietrzyk U, Wienhard K, Heiss WD. Temporal lobe epilepsy: evidence for interictal uncoupling of blood flow and glucose metabolism in temporomesial structures. J Neurol Sci. 1996 Apr;137(1):28-34.

35. Buch K, Blumenfeld H, Spencer S, Novotny E, Zubal IG. Evaluating the accuracy of perfusion/metabolism (SPET/PET) ratio in seizure localization. Eur J Nucl Med Mol Imaging. 2008 Mar;35(3):579-88.

36. Siclari F, Prior JO, Rossetti AO. Ictal cerebral positron emission tomography (PET) in focal status epilepticus. Epilepsy Res. 2013 Aug;105(3):356-61.

37. Guedj E, Aubert S, McGonigal A, Mundler O, Bartolomei F. Déjà-vu in temporal lobe epilepsy: metabolic pattern of cortical involvement in patients with normal brain MRI. Neuropsychologia. 2010 Jun;48(7):2174-81. 
38. Guedj E, McGonigal A, Vaugier L, Mundler O, Bartolomei F. Metabolic brain PET pattern underlying hyperkinetic seizures. Epilepsy Res [Internet]. 2012 Apr 30 [cited 2012 May 9]; Available from: http://www.ncbi.nlm.nih.gov/pubmed/22551665

39. Chassoux F, Semah F, Bouilleret V, Landre E, Devaux B, Turak B, et al. Metabolic changes and electro-clinical patterns in mesio-temporal lobe epilepsy: a correlative study. Brain J Neurol. 2004 Jan;127(Pt 1):164-74.

40. Mauguière F, Ryvlin P. The role of PET in presurgical assessment of partial epilepsies. Epileptic Disord Int Epilepsy J Videotape. 2004 Sep;6(3):193-215.

41. Guedj E, Bonini F, Gavaret M, Trébuchon A, Aubert S, Boucekine M, et al. 18FDG-PET in different subtypes of temporal lobe epilepsy: SEEG validation and predictive value. Epilepsia. 2015 Mar;56(3):414-21.

42. Knowlton RC, Laxer KD, Klein G, Sawrie S, Ende G, Hawkins RA, et al. In vivo hippocampal glucose metabolism in mesial temporal lobe epilepsy. Neurology. 2001 Oct 9;57(7):1184-90.

43. O'Brien TJ, Newton MR, Cook MJ, Berlangieri SU, Kilpatrick C, Morris K, et al. Hippocampal atrophy is not a major determinant of regional hypometabolism in temporal lobe epilepsy. Epilepsia. 1997 Jan;38(1):74-80.

44. Koutroumanidis M, Hennessy MJ, Seed PT, Elwes RD, Jarosz J, Morris RG, et al. Significance of interictal bilateral temporal hypometabolism in temporal lobe epilepsy. Neurology. 2000 May 9;54(9):1811-21.

45. Laschet JJ, Kurcewicz I, Minier F, Trottier S, Khallou-Laschet J, Louvel J, et al. Dysfunction of GABAA receptor glycolysis-dependent modulation in human partial epilepsy. Proc Natl Acad Sci U S A. 2007 Feb 27;104(9):3472-7.

46. Chassoux F. Utilité de la TEP au 18FDG dans l'épilepsie. Méthodes et indications. Médecine Nucléaire. 2009;305-310.

47. Theodore WH. MRI, PET, SPECT: interrelations, technical limits, and unanswered questions. Epilepsy Res Suppl. 1992;5:127-34.

48. Rosenow F, Lüders H. Presurgical evaluation of epilepsy. Brain J Neurol. 2001 Sep;124(Pt 9):1683-700.

49. Willmann O, Wennberg R, May T, Woermann FG, Pohlmann-Eden B. The contribution of 18FFDG PET in preoperative epilepsy surgery evaluation for patients with temporal lobe epilepsy. Seizure. 2007 Sep;16(6):509-20.

50. Chassoux F, Artiges E, Semah F, Desarnaud S, Laurent A, Landre E, et al. Determinants of brain metabolism changes in mesial temporal lobe epilepsy. Epilepsia. 2016 Jun;57(6):907-19.

51. Dodrill CB. Progressive cognitive decline in adolescents and adults with epilepsy. Prog Brain Res. 2002;135:399-407.

52. Elger CE, Helmstaedter C, Kurthen M. Chronic epilepsy and cognition. Lancet Neurol. 2004 Nov;3(11):663-72.

53. Helmstaedter C, Kurthen M. Memory and epilepsy: characteristics, course, and influence of drugs and surgery. Curr Opin Neurol. 2001 Apr;14(2):211-6. 
54. Motamedi G, Meador K. Epilepsy and cognition. Epilepsy Behav EB. 2003 Oct;4 Suppl 2:S25-

38.

55. Guedj E, Barbeau EJ, Liégeois-Chauvel C, Confort-Gouny S, Bartolomei F, Chauvel P, et al. Performance in recognition memory is correlated with entorhinal/perirhinal interictal metabolism in temporal lobe epilepsy. Epilepsy Behav EB. 2010 Dec;19(4):612-7.

56. Varrone A, Asenbaum S, Vander Borght T, Booij J, Nobili F, Någren K, et al. EANM procedure guidelines for PET brain imaging using [18F]FDG, version 2. Eur J Nucl Med Mol Imaging. 2009 Dec;36(12):2103-10.

57. Nguyen NC, Vercher-Conejero JL, Sattar A, Miller MA, Maniawski PJ, Jordan DW, et al. Image Quality and Diagnostic Performance of a Digital PET Prototype in Patients with Oncologic Diseases: Initial Experience and Comparison with Analog PET. J Nucl Med Off Publ Soc Nucl Med. 2015 Sep;56(9):1378-85.

58. Gaillard WD, Bhatia S, Bookheimer SY, Fazilat S, Sato S, Theodore WH. FDG-PET and volumetric MRI in the evaluation of patients with partial epilepsy. Neurology. 1995 Jan;45(1):123-6.

59. Knowlton RC, Laxer KD, Ende G, Hawkins RA, Wong ST, Matson GB, et al. Presurgical multimodality neuroimaging in electroencephalographic lateralized temporal lobe epilepsy. Ann Neurol. 1997 Dec;42(6):829-37.

60. Drzezga A, Arnold S, Minoshima S, Noachtar S, Szecsi J, Winkler P, et al. 18F-FDG PET studies in patients with extratemporal and temporal epilepsy: evaluation of an observer-independent analysis. J Nucl Med Off Publ Soc Nucl Med. 1999 May;40(5):737-46.

61. Uijl SG, Leijten FSS, Arends JBAM, Parra J, van Huffelen AC, Moons KGM. The added value of [18F]-fluoro-D-deoxyglucose positron emission tomography in screening for temporal lobe epilepsy surgery. Epilepsia. 2007 Nov;48(11):2121-9.

62. Kahane $P$, Bartolomei F. Temporal lobe epilepsy and hippocampal sclerosis: lessons from depth EEG recordings. Epilepsia. 2010 Feb;51 Suppl 1:59-62.

63. Sarikaya I. PET studies in epilepsy. Am J Nucl Med Mol Imaging. 2015;5(5):416-30.

64. Semah F, Picot MC, Adam C, Broglin D, Arzimanoglou A, Bazin B, et al. Is the underlying cause of epilepsy a major prognostic factor for recurrence? Neurology. 1998 Nov;51(5):1256-62.

65. Juhász C, Chugani DC, Muzik O, Watson C, Shah J, Shah A, et al. Relationship between EEG and positron emission tomography abnormalities in clinical epilepsy. J Clin Neurophysiol Off Publ Am Electroencephalogr Soc. 2000 Jan;17(1):29-42.

66. Widjaja E, Shammas A, Vali R, Otsubo H, Ochi A, Snead OC, et al. FDG-PET and magnetoencephalography in presurgical workup of children with localization-related nonlesional epilepsy. Epilepsia. 2013 Apr;54(4):691-9.

67. Gok B, Jallo G, Hayeri R, Wahl R, Aygun N. The evaluation of FDG-PET imaging for epileptogenic focus localization in patients with MRI positive and MRI negative temporal lobe epilepsy. Neuroradiology. 2013 May;55(5):541-50.

68. Lamarche F, Job A-S, Deman P, Bhattacharjee M, Hoffmann D, Gallazzini-Crépin C, et al. Correlation of FDG-PET hypometabolism and SEEG epileptogenicity mapping in patients with drugresistant focal epilepsy. Epilepsia. 2016 Nov 8; 
69. Menon RN, Radhakrishnan A, Parameswaran R, Thomas B, Kesavadas C, Abraham M, et al. Does F-18 FDG-PET substantially alter the surgical decision-making in drug-resistant partial epilepsy? Epilepsy Behav EB. 2015 Oct;51:133-9.

70. Kim YK, Lee DS, Lee SK, Chung CK, Chung J-K, Lee MC. (18)F-FDG PET in localization of frontal lobe epilepsy: comparison of visual and SPM analysis. J Nucl Med Off Publ Soc Nucl Med. 2002 Sep;43(9):1167-74.

71. Casse R, Rowe CC, Newton M, Berlangieri SU, Scott AM. Positron emission tomography and epilepsy. Mol Imaging Biol MIB Off Publ Acad Mol Imaging. 2002 Oct;4(5):338-51.

72. Chassoux F. Stereo-EEG: the Sainte-Anne experience in focal cortical dysplasias. Epileptic Disord Int Epilepsy J Videotape. 2003 Sep;5 Suppl 2:S95-103.

73. Salamon N, Kung J, Shaw SJ, Koo J, Koh S, Wu JY, et al. FDG-PET/MRI coregistration improves detection of cortical dysplasia in patients with epilepsy. Neurology. 2008 Nov 11;71(20):1594-601.

74. Dorfmüller G, Ferrand-Sorbets S, Fohlen M, Bulteau C, Archambaud F, Delalande O, et al. Outcome of surgery in children with focal cortical dysplasia younger than 5 years explored by stereoelectroencephalography. Childs Nerv Syst ChNS Off J Int Soc Pediatr Neurosurg. 2014 Nov;30(11):1875-83.

75. Chassoux F, Rodrigo S, Semah F, Beuvon F, Landre E, Devaux B, et al. FDG-PET improves surgical outcome in negative MRI Taylor-type focal cortical dysplasias. Neurology. 2010 Dec 14;75(24):2168-75.

76. Chassoux F, Landré E, Mellerio C, Turak B, Mann MW, Daumas-Duport C, et al. Type II focal cortical dysplasia: electroclinical phenotype and surgical outcome related to imaging. Epilepsia. 2012 Feb;53(2):349-58.

77. Guerrini R, Duchowny M, Jayakar P, Krsek P, Kahane P, Tassi L, et al. Diagnostic methods and treatment options for focal cortical dysplasia. Epilepsia. 2015 Nov;56(11):1669-86.

78. Maillard L, Koessler L, Colnat-Coulbois S, Vignal J-P, Louis-Dorr V, Marie P-Y, et al. Combined SEEG and source localisation study of temporal lobe schizencephaly and polymicrogyria. Clin Neurophysiol Off J Int Fed Clin Neurophysiol. 2009 Sep;120(9):1628-36.

79. Ramantani G, Koessler L, Colnat-Coulbois S, Vignal J-P, Isnard J, Catenoix H, et al. Intracranial evaluation of the epileptogenic zone in regional infrasylvian polymicrogyria. Epilepsia. 2013 Feb;54(2):296-304.

80. da Silva EA, Chugani DC, Muzik O, Chugani HT. Identification of frontal lobe epileptic foci in children using positron emission tomography. Epilepsia. 1997 Nov;38(11):1198-208.

81. Rathore C, Dickson JC, Teotónio R, Ell P, Duncan JS. The utility of 18F-fluorodeoxyglucose PET (FDG PET) in epilepsy surgery. Epilepsy Res. 2014 Oct;108(8):1306-14.

82. Swartz BW, Khonsari A, Vrown C, Mandelkern M, Simpkins F, Krisdakumtorn T. Improved sensitivity of 18FDG-positron emission tomography scans in frontal and "frontal plus" epilepsy. Epilepsia. 1995 Apr;36(4):388-95.

83. Hartl E, Rémi J, Vollmar C, Goc J, Loesch AM, Rominger A, et al. PET imaging in extratemporal epilepsy requires consideration of electroclinical findings. Epilepsy Res. 2016 Sep;125:72-6. 
84. Morales-Chacon LM, Alfredo Sanchez Catasus C, Minou Baez Martin M, Rodriguez Rojas R, Lorigados Pedre L, Estupiñan Diaz B. Multimodal imaging in nonlesional medically intractable focal epilepsy. Front Biosci Elite Ed. 2015 Jan 1;7:42-57.

85. De Ciantis A, Barba C, Tassi L, Cosottini M, Tosetti M, Costagli M, et al. 7T MRI in focal epilepsy with unrevealing conventional field strength imaging. Epilepsia. 2016 Mar;57(3):445-54.

86. Téllez-Zenteno JF, Dhar R, Hernandez-Ronquillo L, Wiebe S. Long-term outcomes in epilepsy surgery: antiepileptic drugs, mortality, cognitive and psychosocial aspects. Brain J Neurol. 2007 Feb;130(Pt 2):334-45.

87. LoPinto-Khoury C, Sperling MR, Skidmore C, Nei M, Evans J, Sharan A, et al. Surgical outcome in PET-positive, MRI-negative patients with temporal lobe epilepsy. Epilepsia. 2012 Feb;53(2):342-8.

88. Immonen A, Jutila L, Muraja-Murro A, Mervaala E, Äikiä M, Lamusuo S, et al. Long-term epilepsy surgery outcomes in patients with MRI-negative temporal lobe epilepsy. Epilepsia. 2010 Nov;51(11):2260-9.

89. Murphy MA, O'Brien TJ, Morris K, Cook MJ. Multimodality image-guided surgery for the treatment of medically refractory epilepsy. J Neurosurg. 2004 Mar;100(3):452-62.

90. Lee KK, Salamon N. [18F] fluorodeoxyglucose-positron-emission tomography and MR imaging coregistration for presurgical evaluation of medically refractory epilepsy. AJNR Am J Neuroradiol. 2009 Nov;30(10):1811-6.

91. Henry TR, Babb TL, Engel J, Mazziotta JC, Phelps ME, Crandall PH. Hippocampal neuronal loss and regional hypometabolism in temporal lobe epilepsy. Ann Neurol. 1994 Dec;36(6):925-7.

92. Semah F, Baulac M, Hasboun D, Frouin V, Mangin JF, Papageorgiou S, et al. Is interictal temporal hypometabolism related to mesial temporal sclerosis? A positron emission tomography/magnetic resonance imaging confrontation. Epilepsia. 1995 May;36(5):447-56.

93. Halac G, Delil S, Zafer D, Isler C, Uzan M, Comunoglu N, et al. Compatibility of MRI and FDGPET findings with histopathological results in patients with focal cortical dysplasia. Seizure. 2016 Dec 6;45:80-6.

94. Shin HW, Jewells V, Sheikh A, Zhang J, Zhu H, An H, et al. Initial experience in hybrid PET-MRI for evaluation of refractory focal onset epilepsy. Seizure. 2015 Sep;31:1-4.

95. Knowlton RC, Elgavish RA, Bartolucci A, Ojha B, Limdi N, Blount J, et al. Functional imaging: II. Prediction of epilepsy surgery outcome. Ann Neurol. 2008 Jul;64(1):35-41.

96. Dupont S, Semah F, Clémenceau S, Adam C, Baulac M, Samson Y. Accurate prediction of postoperative outcome in mesial temporal lobe epilepsy: a study using positron emission tomography with 18fluorodeoxyglucose. Arch Neurol. 2000 Sep;57(9):1331-6.

97. Vinton $A B$, Carne R, Hicks RJ, Desmond PM, Kilpatrick C, Kaye AH, et al. The extent of resection of FDG-PET hypometabolism relates to outcome of temporal lobectomy. Brain J Neurol. 2007 Feb;130(Pt 2):548-60.

98. Juhász C, Chugani DC, Muzik O, Shah A, Shah J, Watson C, et al. Relationship of flumazenil and glucose PET abnormalities to neocortical epilepsy surgery outcome. Neurology. 2001 Jun 26;56(12):1650-8. 
99. Rausch R, Henry TR, Ary CM, Engel J, Mazziotta J. Asymmetric interictal glucose hypometabolism and cognitive performance in epileptic patients. Arch Neurol. 1994 Feb;51(2):13944.

100. Arnold S, Schlaug G, Niemann H, Ebner A, Lüders H, Witte OW, et al. Topography of interictal glucose hypometabolism in unilateral mesiotemporal epilepsy. Neurology. 1996 May;46(5):1422-30.

101. Akanuma N, Reed LJ, Marsden PK, Jarosz J, Adachi N, Hallett WA, et al. Hemisphere-specific episodic memory networks in the human brain: a correlation study between intracarotid amobarbital test and [(18)F]FDG-PET. J Cogn Neurosci. 2009 Mar;21(3):605-22.

102. Weintrob DL, Saling MM, Berkovic SF, Berlangieri SU, Reutens DC. Verbal memory in left temporal lobe epilepsy: evidence for task-related localization. Ann Neurol. 2002 Apr;51(4):442-7.

103. Griffith HR, Richardson E, Pyzalski RW, Bell B, Dow C, Hermann BP, et al. Memory for famous faces and the temporal pole: functional imaging findings in temporal lobe epilepsy. Epilepsy Behav EB. 2006 Aug;9(1):173-80.

104. Trebuchon-Da Fonseca A, Guedj E, Alario F-X, Laguitton V, Mundler O, Chauvel P, et al. Brain regions underlying word finding difficulties in temporal lobe epilepsy. Brain J Neurol. 2009 Oct;132(Pt 10):2772-84.

105. Spanaki MV, Kopylev L, DeCarli C, Gaillard WD, Liow K, Fazilat S, et al. Postoperative changes in cerebral metabolism in temporal lobe epilepsy. Arch Neurol. 2000 Oct;57(10):1447-52.

106. Knopman AA, Wong CH, Stevenson RJ, Homewood J, Mohamed A, Somerville E, et al. The cognitive profile of occipital lobe epilepsy and the selective association of left temporal lobe hypometabolism with verbal memory impairment. Epilepsia. 2014 Aug;55(8):e80-84.

107. Verger A, Yagdigul Y, Van Der Gucht A, Poussier S, Guedj E, Maillard L, et al. Temporal epilepsy lesions may be detected by the voxel-based quantitative analysis of brain FDG-PET images using an original block-matching normalization software. Ann Nucl Med. 2016 May;30(4):272-8.

108. van't Klooster MA, Huiskamp G, Zijlmans M, Debets RMC, Comans EFI, Bouvard S, et al. Can we increase the yield of FDG-PET in the preoperative work-up for epilepsy surgery? Epilepsy Res. 2014 Aug;108(6):1095-105.

109. Mayoral M, Marti-Fuster B, Carreño M, Carrasco JL, Bargalló N, Donaire A, et al. Seizure-onset zone localization by statistical parametric mapping in visually normal (18) F-FDG PET studies. Epilepsia. 2016 Aug;57(8):1236-44.

110. Wang K, Liu T, Zhao X, Xia X, Zhang K, Qiao H, et al. Comparative Study of Voxel-Based Epileptic Foci Localization Accuracy between Statistical Parametric Mapping and Three-dimensional Stereotactic Surface Projection. Front Neurol. 2016;7:164.

111. Kim YK, Lee DS, Lee SK, Kim S-K, Chung CK, Chang KH, et al. Differential features of metabolic abnormalities between medial and lateral temporal lobe epilepsy: quantitative analysis of (18)F-FDG PET using SPM. J Nucl Med Off Publ Soc Nucl Med. 2003 Jul;44(7):1006-12.

112. Lee JJ, Kang WJ, Lee DS, Lee JS, Hwang H, Kim KJ, et al. Diagnostic performance of 18F-FDG PET and ictal 99mTc-HMPAO SPET in pediatric temporal lobe epilepsy: quantitative analysis by statistical parametric mapping, statistical probabilistic anatomical map, and subtraction ictal SPET. Seizure J Br Epilepsy Assoc. 2005 Apr;14(3):213-20. 
113. Van Bogaert $P$, Massager $N$, Tugendhaft $P$, Wikler D, Damhaut $P$, Levivier $M$, et al. Statistical parametric mapping of regional glucose metabolism in mesial temporal lobe epilepsy. Neurolmage. 2000 Aug;12(2):129-38.

114. Signorini M, Paulesu E, Friston K, Perani D, Colleluori A, Lucignani G, et al. Rapid assessment of regional cerebral metabolic abnormalities in single subjects with quantitative and nonquantitative [18F]FDG PET: A clinical validation of statistical parametric mapping. Neurolmage. 1999 Jan;9(1):6380.

115. Goffin K, Van Paesschen W, Dupont P, Baete K, Palmini A, Nuyts J, et al. Anatomy-based reconstruction of FDG-PET images with implicit partial volume correction improves detection of hypometabolic regions in patients with epilepsy due to focal cortical dysplasia diagnosed on MRI. Eur J Nucl Med Mol Imaging. 2010 Jun;37(6):1148-55.

116. Hammers A. Flumazenil positron emission tomography and other ligands for functional imaging. Neuroimaging Clin N Am. 2004 Aug;14(3):537-51.

117. Yankam Njiwa J, Bouvard S, Catenoix H, Mauguiere F, Ryvlin P, Hammers A. Periventricular $[(11) C]$ flumazenil binding for predicting postoperative outcome in individual patients with temporal lobe epilepsy and hippocampal sclerosis. Neurolmage Clin. 2013;3:242-8.

118. Koepp MJ, Hammers A, Labbé C, Woermann FG, Brooks DJ, Duncan JS. 11C-flumazenil PET in patients with refractory temporal lobe epilepsy and normal MRI. Neurology. 2000 Jan 25;54(2):3329.

119. Salmi E, Aalto S, Hirvonen J, Långsjö JW, Maksimow AT, Oikonen V, et al. Measurement of GABAA receptor binding in vivo with [11C]flumazenil: a test-retest study in healthy subjects. Neurolmage. 2008 Jun;41(2):260-9.

120. Merlet I, Ostrowsky K, Costes N, Ryvlin P, Isnard J, Faillenot I, et al. 5-HT1A receptor binding and intracerebral activity in temporal lobe epilepsy: an [18F]MPPF-PET study. Brain J Neurol. 2004 Apr;127(Pt 4):900-13.

121. Merlet I, Ryvlin P, Costes N, Dufournel D, Isnard J, Faillenot I, et al. Statistical parametric mapping of 5-HT1A receptor binding in temporal lobe epilepsy with hippocampal ictal onset on intracranial EEG. Neurolmage. 2004 Jun;22(2):886-96.

122. McGinnity CJ, Shidahara M, Feldmann M, Keihaninejad S, Riaño Barros DA, Gousias IS, et al. Quantification of opioid receptor availability following spontaneous epileptic seizures: correction of [11C]diprenorphine PET data for the partial-volume effect. Neurolmage. 2013 Oct 1;79:72-80.

123. DuBois JM, Rousset OG, Guiot M-C, Hall JA, Reader AJ, Soucy J-P, et al. Metabotropic Glutamate Receptor Type 5 (mGluR5) Cortical Abnormalities in Focal Cortical Dysplasia Identified In Vivo With [11C]ABP688 Positron-Emission Tomography (PET) Imaging. Cereb Cortex N Y N 1991. 2016 Aug 30;

124. Gershen LD, Zanotti-Fregonara P, Dustin IH, Liow J-S, Hirvonen J, KreisI WC, et al. Neuroinflammation in Temporal Lobe Epilepsy Measured Using Positron Emission Tomographic Imaging of Translocator Protein. JAMA Neurol. 2015 Aug;72(8):882-8.

125. McGinnity CJ, Koepp MJ, Hammers A, Riaño Barros DA, Pressler RM, Luthra S, et al. NMDA receptor binding in focal epilepsies. J Neurol Neurosurg Psychiatry. 2015 Oct;86(10):1150-7. 
126. Fedi M, Reutens D, Okazawa H, Andermann F, Boling W, Dubeau F, et al. Localizing value of alpha-methyl-L-tryptophan PET in intractable epilepsy of neocortical origin. Neurology. 2001 Nov 13;57(9):1629-36.

127. Natsume J, Kumakura Y, Bernasconi N, Soucy J-P, Nakai A, Rosa P, et al. Alpha-[11C] methyl-Ltryptophan and glucose metabolism in patients with temporal lobe epilepsy. Neurology. 2003 Mar $11 ; 60(5): 756-61$.

128. Juhász C, Chugani DC, Muzik O, Shah A, Asano E, Mangner TJ, et al. Alpha-methyl-Ltryptophan PET detects epileptogenic cortex in children with intractable epilepsy. Neurology. 2003 Mar 25;60(6):960-8.

129. Gidal BE, French JA, Grossman P, Le Teuff G. Assessment of potential drug interactions in patients with epilepsy: impact of age and sex. Neurology. 2009 Feb 3;72(5):419-25. 


\section{Figure Legends}

\section{Figure 1.}

Axial slices of perfusion SPECT imaging in ictal phase (A), inter-ictal phase (B) and after subtraction of ictal and inter-ictal SPECT images co-registered to MRI (SISCOM, C) in a 40 years-old man with right temporal epilepsy. A hyperperfusion is noticed in right mesial temporal area (white arrow in A), which is hypoperfused in inter-ictal state (white arrow in B). The subtraction of ictal and inter-ictal states reveals a significant differential in perfusion in this same area, which corresponds to right mesial temporal lobe when co-registered to MRI (white arrow in C).

\section{Figure 2.}

Axial slices of T1-weighted-sequence MRI (A), ${ }^{18}$ F-FDG PET imaging (B) and coregistration of MRI and PET imaging $(\mathrm{C})$ in a 35 years-old woman with right temporo-insular epilepsy. MRI was interpreted as negative (A). ${ }^{18}$ F-FDG PET shows a hypometabolism in right insulo-opercular area (white arrow in B and C).

\section{Figure 3.}

Multimodality pre-operative assessment in a patient of 39 years-old with pharmaco-resistant seizures. The seizures were characterized by dreamy state (“déjà-vu”), visual complex hallucination (object size modification), eyes staring, consciousness alteration and oral automatisms. The cerebral MRI was normal. The patient was operated of right temporal 
lobectomy from the temporal pole until posterior hippocampus. The histology revealed a focal cortical dysplasia. The patient improved significantly after surgery (Engel Classe II after 2 years of follow-up). Axial slices of SPECT imaging (A) showed a hypoperfusion in inter-ictal state (upper panel, white arrow), a hyperperfusion in ictal state (middle panel, white arrow) and a significant differential of perfusion after subtraction of ictal and inter-ictal state (lower panel, white arrow in A and 3D render volume in B) of the right temporal pole. PET imaging (C) showed a hypometabolism in the right temporal lobe in axial slice (upper panel, white arrow) and in coronal slice (lower panel, white arrow). The SEEG ictal recording (D) showed an EZ including (most rapid discharges): right temporal pole (TP 1-2-3), temporo-basal cortex (TB 2-3-4), amygdala (A1-2-3), anterior (B1-2-3) and posterior (C1-2-3) hippocampus and middle temporal gyrus (A13-14). In this patient was also implanted electrodes recording: lateral temporal cortex (TP9-10, TB9-10-11, A13-14, B11-12-13, C13-14, H14-15), frontal opercula (OF8-9), occipito-temporal junction (OT1-2, OT9-10) and anterior insula (OF1-2).

\section{Figure 4.}

Anatomical localization with quantitative analysis, using SPM 8 software in a 31 years-old man with right temporal epilepsy, after comparison to PET images of a normal local database $(n=18)$. Results are projected onto 3D volume rendering $(A)$ and sections of a normal MRI centered on right mesial temporal area (B) and set spatially normalized and smoothed into the standard SPM8 template after using an inclusive right mesial temporal mask. A hypometabolism is noticed in right mesial temporal lobe $(\mathrm{p}<0.05$, with correction for multiple comparisons). 
Figure 1
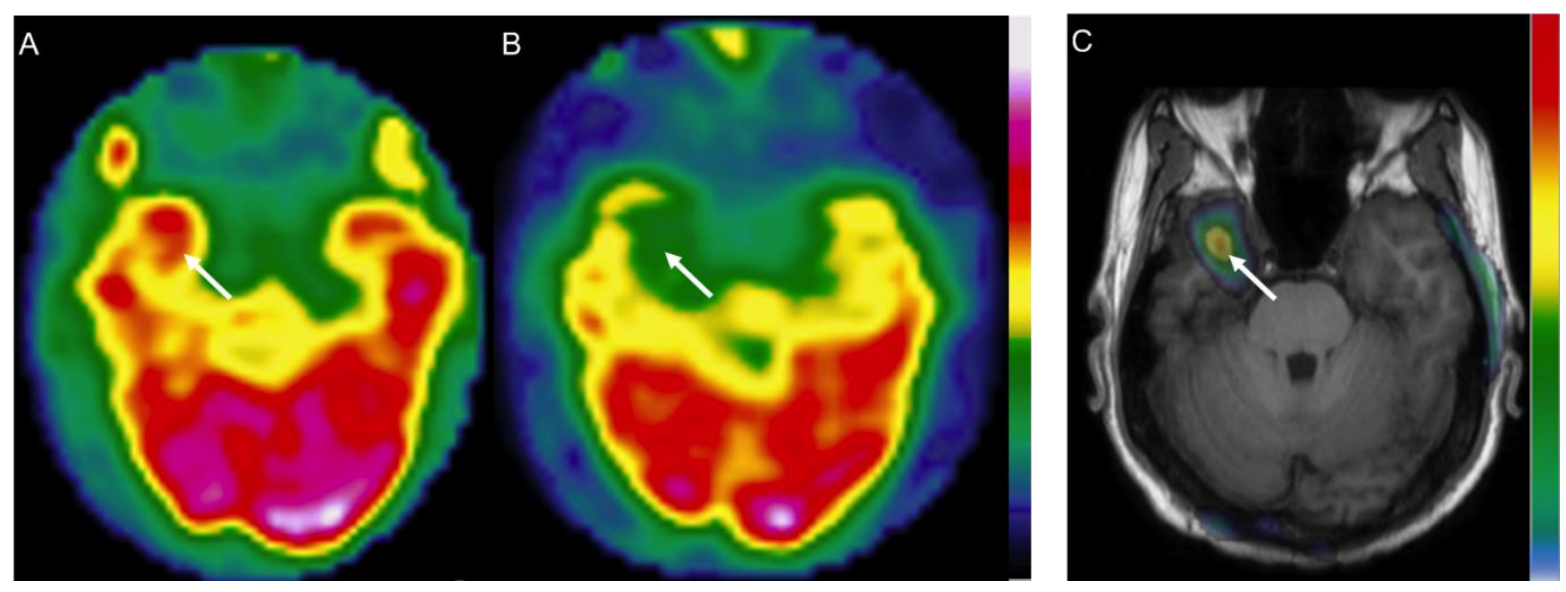
Figure 2

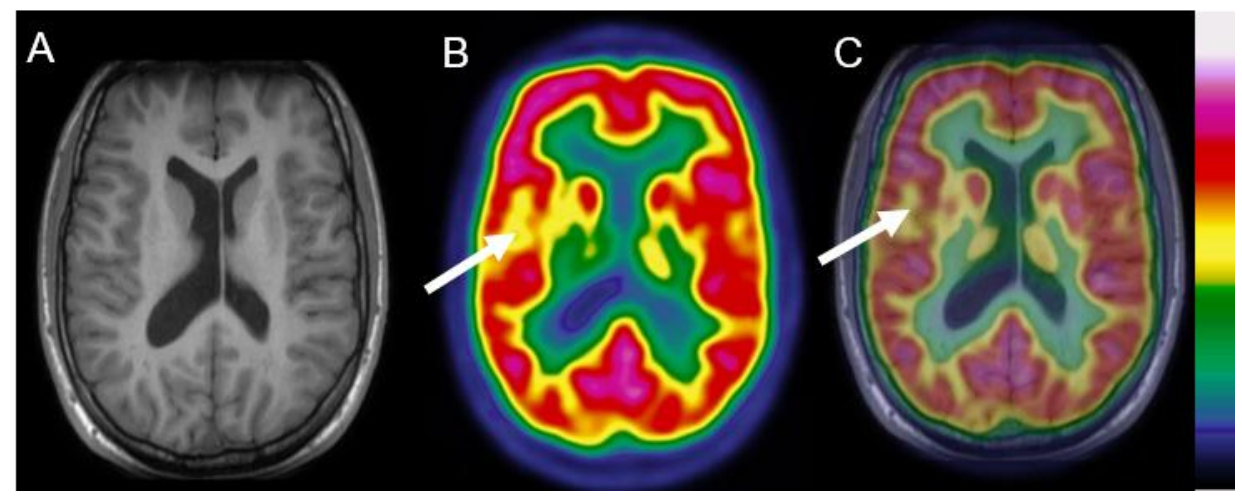


Figure 3

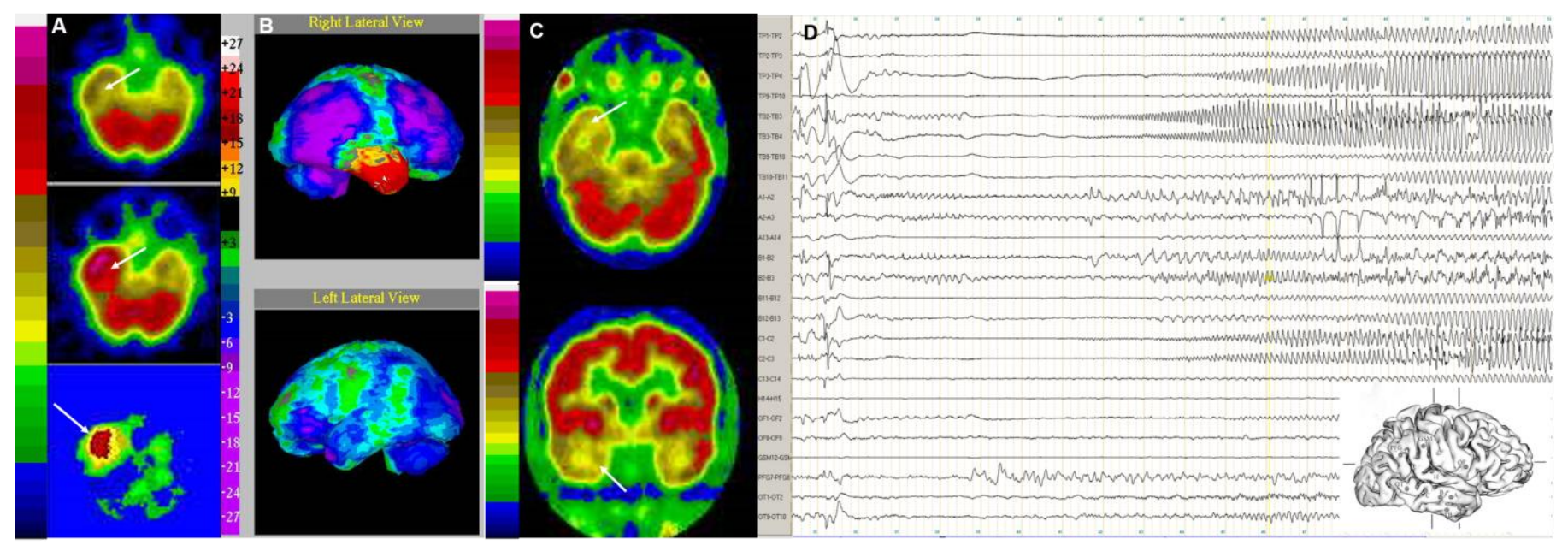


Figure 4
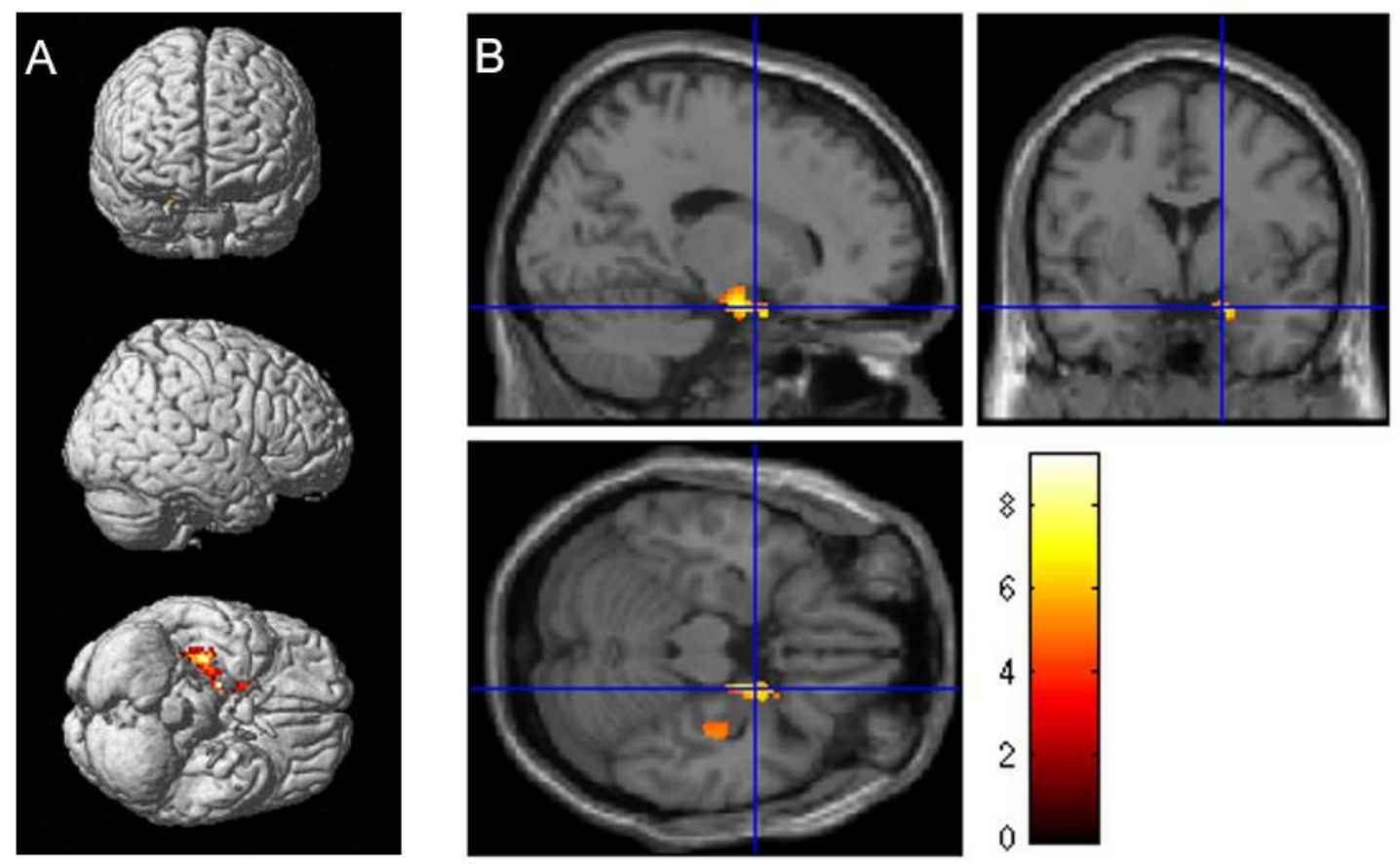

8
6
4
2
0 